\title{
Get Involved: Subhadarshi Nayak, TMS Professional Registration Committee
}

\section{Kelly Zappas}

"Get Involved" is a recurring End Notes feature that spotlights the work of TMS volunteers and shows the wide range of activities available through TMS. This month features Subhadarshi Nayak, founder of ScienceTomorrow, LLC and chair of the TMS Professional Registration Committee.

Q. What does the TMS Professional Registration Committee do?

A. The Professional Registration Committee is the TMS liaison that works with the National Council of Examiners for Engineering and Surveying to conduct the examination for the Professional Engineer (PE) License in Metallurgical and Materials Engineering. In other words, this committee makes PE licensing in our profession possible.

Q. What roles do volunteers play in TMS Professional Registration activities?

A. This committee is primarily responsible for developing exam content. Our volunteers work really hard in developing examination questions that meet several criteria. We also help determine pass/fail criteria and determine the course content (specification) for the exam. I think it is one of the very few (if not only) committees that really "study" materials science as part of committee business. It is quite heartening to see that the volunteers carry out their business with phase diagram books opened in their hands. Getting involved in this committee helps me to continually refresh my knowledge of the foundations of materials science and expand to new areas.

Q. How did you become involved with this committee?
A. I find TMS is a valuable element in my career development strategy. I look forward to any opportunity where I can contribute to TMS (and thereby get involved). After I got my PE license, I saw an opportunity to contribute to the committee, and I joined. Looking back, it was the best career development step I have ever taken.

Q. Is your committee currently seeking additional volunteers? If so, what roles do you need them to fill and how can they get involved?

A. Yes, we are always looking for subject matter expert volunteers (especially from industry) to contribute to our activities. Since the examination items need to be refreshed and replaced continually, we need volunteers to write questions in divergent subject matters. The volunteers MUST have a PE license BEFORE they can join our committee.

Q. How much time do you commit to your volunteer activities with TMS? Is it difficult to balance your work and volunteer commitments?

A. I have taken many opportunities to volunteer for TMS. As an entrepreneur, I do have flexibility. In fact, getting involved in TMS is part of my "job" as a business owner.

Q. How has volunteering with TMS Professional Registration ac-

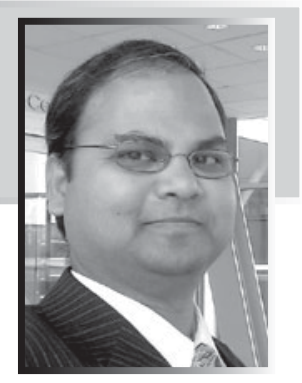

tivities helped you professionally?

A. I have developed relationships through this committee that have helped me in establishing my business. I get to know people who have directly gotten me business and provided leads that have helped me get business. I get to know different subject matter experts who can advise me in specific technical problems and mentor me in business-related issues. It is an invaluable resource for me.

Besides, working exam questions and revising specifications have helped me to stay abreast in the materials science field, which in turn helps me in business. Had I not joined this committee, I would not get the time or resources to learn the basics in such diverse materials and processes. Hence, I am so glad I did.

Kelly Zappas is a contributing writer for TMS.

If you are a licensed Professional Engineer who would like to serve as a subject matter expert on the TMS Professional Registration Committee, contact Subhadarshi Nayak at nayak.subu@gmail.com. If you know of a TMS member who should be featured in a future "Get Involved" column, contact Kelly Zappas atkzappas@tms.org. 